\title{
Research on the Practical Application of Ideological and Political Education under the Trend of Interdisciplinary Integration and Big Data Technology
}

\author{
Yi-nan $\mathrm{Fu}^{1, \mathrm{a}}$ \\ ${ }^{1}$ School of Marxism, Guilin University of Electronic Technology, Gulin, Guangxi, China \\ a670184087@qq.com
}

\begin{abstract}
Keywords: Interdisciplinary integration, Big data technology, Ideological and political education, Practical application.
\end{abstract}

\begin{abstract}
The purpose of interdisciplinary integration is to bridge the gap between disciplines, enhance the interaction between disciplines and solve more complex scientific problems. The application of big data technology is using data resources, combined with data thinking mode, to predict and judge.As a new form of fusion of many kinds of disciplines, the realistic application of ideological and political education has the characteristics of interdisciplinary fusion and the dynamic characteristics of big data technology, which is reflected in promoting the symbiosis of fusion to the stage of in-depth development. So as to strengthen the guidance of mainstream public opinion and consolidate the common ideological foundation; The dynamic nature is embodied in the process from the birth of the new media to the development of big data precision technology, which drives the ideological and political education into scientific, digital and technological changes.
\end{abstract}

\section{Introduction}

The ideological and political education has changed from "single" to "combination", and the ideological and political course has changed from "roll call class" to "network celebrity class". The hot rise of interdisciplinary research and the deep promotion of big data technical application will bring about changes in the ways and means of ideological and political education. As Marx said, if a discipline realizes diversification and precision, it can be regarded as a mature discipline. In view of this, we should closely revolve around the research main line of the era development and dynamic trend, grasp the new characteristics and new laws of the realistic application of ideological and political education in the new era, new period and new situation, improve the practical operation of ideological and political education, and enhance the practice of ideological and political education, and construct the practical application system of ideological and political education and go out of the way of connotative development in the discipline of deepening innovation.

\section{The research progress of the practical application of ideological and political education}

Interdisciplinary, from the western literature of the 1920s, refers to the intersection of subjects and the creation of knowledge; the head of the big data technology is found in the McKinsey study and emphasizes the use of mass data for predicting development in the field. In this regard, based on the background of the present era, the ideological and political education with practical application of interdisciplinary integration and big data technology will also show different forms and features.

\subsection{Ideological and political education and development power}

Interdisciplinary integration is the driving force to promote ideological and political education, using big data technology to promote ideological and political education. The ideological and political education itself is an activity centered on theory and practice, we regard interdisciplinary integration as theoretical increment, and big data technology as practical promoter.Taking the "virtual human relationship" of ideological and political education as an example, we first apply the 
interdisciplinary fusion of literature, philosophy and sociology, the integration of excellent cultural and educational resources such as socialist core values, "social justice" in the West and "cautious independence" and "harmony" in ancient times, promote the virtual interpersonal relationship to "harmonious virtual and reality". Secondly, in conjunction with the data management, collection and comparison analysis of big data technology, effective intervention for virtual human relationships in different groups, resolutely eliminate decadent and wrong virtual interpersonal relationships.

\subsection{Ideological and political education and inherent motive force}

Taking interdisciplinary integration as the inherent driving force of enriching ideological and political education, using big data technology to make ideological and political education even better. Ideological and political education itself is an activity focusing on the dissemination of ideas, we regard interdisciplinary integration as a prerequisite for thought orientation, and big data technology as an inevitable requirement for effect optimization. Taking the website construction of ideological and political education as an example, first of all, in view of the different types of ideological and political education websites into the due subject characteristics, it is the core of the communication as the content, and is the key to the group interaction of psychology, which is supplemented by the teaching of the material of the pedagogy. Secondly, relying on the data retrieval, processing and optimal arrangement of big data technology, this paper makes an accurate analysis and calculation of the number of visits, hits and readings of the ideological and political education website, so as to create a fine version and optimize the communication strategy.

\subsection{Ideological and political education and derivative motivation}

Taking interdisciplinary integration as the derivative power of innovative ideological and political education, using big data technology to contribute to ideological and political education. The ideological and political education itself is an activity of the combination of a guiding concept and a standard morality. we regard interdisciplinary integration as the foundation stone, and big data technology as the sail of long voyage. Taking the ideological and political education under the network public opinion as an example, first of all, network public opinion usually covers economic and political, cultural entertainment, social hot spots and other aspects, through interdisciplinary integration to improve the effect of ideological and political education in network public opinion. Secondly, it is in line with big data technology, such as the monitoring of public opinion heat, the semantic analysis of public opinion and the research and judgment of public opinion attitude, which is easy to form measures to deal with and resolve the problems and crises of public opinion, so as to strengthen the radiation, penetration and influence of ideological and political education in the guidance of network public opinion.

\section{Difficulties and dilemmas in the practical application of ideological and political education}

When ideological and political education with interdisciplinary integration, and using big data technology, we are aware of the advantages and benefits of interdisciplinary integration and big data technology for ideological and political education, which have carried on the positive beneficial attempt and the grope, but in the course of practical application, still facing many problems, such as boundary range, system model, privacy and security, and so on. Its practical application is a long way to go.

\subsection{The difficulties in interdisciplinary integration of ideological and political education}

First of all, interdisciplinary integration is easy to dislocate and offset. Improper grasp of the subject nature and attribute of ideological and political education, applying only the concept, expression and mode of ideological and political education, it has not actually penetrated into the cross-area between ideological and political education and other disciplines, that is, the interdisciplinary integration of interior and essence can not be realized. There is even a complete deviation of the 
subject, resulting in the result of "four dissimilarities" in the process of practical application. Secondly, the boundary of interdisciplinary integration is blurred. The existence of traditional disciplines, similar disciplines, marginal disciplines and branches of ideological and political education, making the subject ownership an obstacle. In addition, with the multidimensional research direction and diversity of research results, the ideological and political education system is becoming more and more huge. In the process of interdisciplinary integration, it is easy to have the phenomenon of interdisciplinary confusion and complicated thinking, so that fusion overlaps and innovation stagnates.

\subsection{The dilemmas of using big data technology in ideological and political education}

Firstly, the identification of effective data is difficult. When the vast amount of data about ideological and political education is presented in front of us, how to identify the data that can be used by us under the condition of legal morality and technical support, and extract valid data from it and delete redundant data, this is the first question to be answered in the application of big data technology in ideological and political education. Secondly, the effective system has not yet been developed. The existing data systems serve decision-making, the design principle is based on the completion of the transaction step by step, that is, the existing data as the end point. And ignoring the key concept that "the subject and object of ideological and political education are both human". The data system can not track the change and growth process of human ideological and political education dynamically, it is impossible to periodically manage, update, check, synchronize and share the data of ideological and political education.

\section{Exploration on the trend of practical Application of ideological and political education}

For practical application, the significance of interdisciplinary integration and big data technology lies not only in promoting the high integration of ideological and political education and network technology discipline, but also in matching diversified disciplines for big data technology in different stages, thus providing services and support for the in-depth analysis of ideological and political education information data. Based on the research progress difficulties and dilemmas, taking the working process of big data analysis and treatment of the interdisciplinary integration of ideological and political education as the carrier, exploring the "digitalization" and "technicalization" of ideological and political education.

\subsection{The starting point of interdisciplinary integration: building the basic database of ideological and political education}

The so-called basic database refers to the small capacity and representative, concise and clear data at a glance. Through the data set with the highest risk coefficient and unstable trend, doing a good job in the ideological and political education planning of "guiding according to the situation" in advance. The core of the database lies in the data index of ideological and political education, the data index should conform to the nature, principle, law, task and environment of ideological and political education. Therefore, in order to build the database, it is necessary to integrate sociology, psychology and political science, such as participation in party and mass organization activities, the situation and performance of public welfare and volunteer activities. Secondly, the data cleaning and integration are carried out by using statistics, quantitative economics and big data algorithm, and finally the basic database is synthesized.

\subsection{The intermediary of interdisciplinary integration: building the intelligent management system of ideological and political education}

The so-called intelligent management system is based on the premise of real-time updating, synchronization and sharing of data, driven by a stable and harmonious ecological structure. It can not only systematically evaluate the ideological and political education work, but also make early warning and forecast of the ideological and political education crisis. Therefore, to construct the intelligent management system, we need to integrate logic, operation research and evaluation. The 
evaluation is no longer determined by the results generated by the final system, but pays more attention to the process indicators in the early stage. To change the evaluation of ideological and political education from the traditional "important result" to the due "vital process".Secondly, combining management science and public opinion analysis, the intelligent management system is embedded in the early warning and prediction rules, when the acquired data triggers or matches the rule, a prompt is sent and the corresponding judgment is made.

\subsection{The result of interdisciplinary integration: building the information guarantee system of ideological and political education}

The so-called information security system is to clarify the problem that big data technology can be done and cannot be done, ensuring data security and privacy while breaking out "digital islet". Therefore, to build the information guarantee system, it is necessary to integrate cryptography, cloud computing and big data security, e-government security and so on, and desensitize the relevant data and follow the principle of "people-oriented". The key to the system is to correctly use the data to understand the dynamics of human thought and behavior. The favorable results obtained from the analysis of ideological and political education data should be guided by good inducement. For example, the data of the activity of ideological and political classroom are obviously improved, and the methods should be summarized to expand the advantages of the classroom. And immediate intervention is obtained from the analysis of ideological and political education data. For example, data tracking shows the possibility of security risks or suicidal tendencies, which should be prevented in accordance with emergency plans.

\section{Acknowledgment}

This research was financially supported by GUET Excellent Graduate Thesis Program "A study on the discourse mode of the international dissemination of socialist core values--take political discourse as an example" (Grant NO.17YJPYSS35) and Innovation Project of GUET Graduate Education "A study on the discourse mode of overseas dissemination of socialist core values under the background of 'Belt and Road Initiative' " (Grant NO.2019YCXS122).

\section{References}

[1] $\mathrm{Hu}$ Yudong and $\mathrm{Hu}$ Gaoquan, the Present Situation, Dilemma and Exploration of Big Data Application in Ideological and Political Education in Colleges and Universities, Journal of Chongqing University of Technology (Social Science), vol.5, pp. 1-11, 2019.

[2] Wang Dongliang, Ideological and political Education in Big Data Era Requires Scientific Construction of Object Grasp Mechanism, Ideological and Theoretical Education, vol.7, pp.84-87, 2018

[3] Wang Hongwei, Promoting Interdisciplinary Research in Ideological and Political Education, Ideological and Theoretical Education, vol.4, pp.58-63, 2015.

[4] Ye Fangxing, on the Interdisciplinary Study of Ideological and Political Education, Ideological Education Research, vol.9, pp.16-19, 2013. 